\title{
Preoperative Exercise Testing Is a Better Predictor of Postoperative Complications than Pulmonary Function Testing for Patients with Lung Cancer
}

\author{
Atsushi Hata1, Yasuo Sekine ${ }^{1 *}$, Eitetsu Koh1, Nobuyuki Yamaguchi2 \\ ${ }^{1}$ Department of Thoracic Surgery, Tokyo Women's Medical University Yachiyo Medical Center, Yachiyo, Japan \\ ${ }^{2}$ Division of Clinical Physiology, Tokyo Women's Medical University Yachiyo Medical Center, Yachiyo, Japan \\ Email: sekine.yasuo@twmu.ac.jp
}

Received 23 February 2015; accepted 24 March 2015; published 27 March 2015

Copyright (C) 2015 by authors and Scientific Research Publishing Inc.

This work is licensed under the Creative Commons Attribution International License (CC BY). http://creativecommons.org/licenses/by/4.0/

\section{(c) (i) Open Access}

\section{Abstract}

Objective: The aim of this preliminary study was to evaluate the feasibility of exercise testing (ET) for predicting postoperative complications in patients with impaired pulmonary function. Methods: Thirteen patients were prospectively enrolled. The enrollment criteria were $\mathrm{FEV}_{1.0} \%<70 \%$ and emphysema score $>8$ by the Goddard classification or interstitial pneumonia on chest computed tomography. Patients underwent testing for pulmonary function, six-minute walking test (6MWT), and stair-climbing test (SCT). Postoperative cardiopulmonary complications (PCPCs) were recorded. Results: Four patients developed PCPCs. There were no significant differences between the patients with PCPCs $(n=4)$ and those without PCPCs $(n=9)$ for background data and PFT. The distances achieved in the 6MWT were $503 \pm 72.7 \mathrm{~m}$ for patients without PCPCs and $369 \pm$ $50.7 \mathrm{~m}$ for patients with PCPCs $(p=0.011)$. The SCT climbing heights were $20.4 \pm 5.3 \mathrm{~m}$ for patients without PCPCs and $14.9 \pm 4.0 \mathrm{~m}$ for patients with PCPCs $(P=0.187)$. Cut-off points, including a 6MFT distance of less than $400 \mathrm{~m}$, SCT height lower than $15 \mathrm{~m}$, and SCT climbing speed less than $8.5 \mathrm{~m} / \mathrm{min}$, were predictive of CPCP. Conclusions: Exercise testing is more feasible for predicting postoperative cardiopulmonary complications than stationary pulmonary function testing.

\section{Keywords}

Lung Cancer, Exercise Testing, Postoperative Complication, Pulmonary Function Testing

\footnotetext{
${ }^{*}$ Corresponding author.
} 


\section{Introduction}

Pulmonary resection is a standard treatment option for patients with stage I and II non-small cell lung cancer. Preoperative physiologic evaluation is mandatory for resection of one or more pulmonary lobes. The American College of Chest Physicians (ACCP) has proposed evidence-based clinical practice guidelines for preoperative physiologic evaluation of patients with lung cancer [1]. The guidelines present a risk assessment algorithm, which recommends that patients with abnormal results on pulmonary function testing (PFT) undergo additional testing, such as diffusing capacity of the lung for carbon monoxide (DLco) and cardiopulmonary exercise testing (CPET). However, sometimes the predicted postoperative (PPO) pulmonary function is underestimated and the actual postoperative physiologic capacity has no relationship to the predicted capacity [2].

Lung volume reduction surgery has been found to be beneficial for patients with heterogeneous emphysema, and lobectomy has also been shown to be beneficial for patients with a malignant tumor located in an upper emphysematous lobe [3]. These findings suggest that postoperative lung function and exercise capacity may differ based on the physiologic or anatomic pulmonary abnormalities and the volume of lung resected.

Criteria for safe lung resection have been reported, but they may over- or underestimate the risk of postoperative cardiopulmonary complications (PCPCs) in patients who undergo lung surgery [4], because PFT only estimates pulmonary function and does not evaluate cardiac function. Furthermore, since the estimation of PPO PFT is based on the number of segments to be resected, the risk for patients with emphysema could be overestimated if the lung resection benefits the patient because of the reduction in volume of emphysematous lung. On the other hand, CPET can evaluate cardiopulmonary function and oxygen transport [5]. CPET can reveal serious pathophysiologic abnormalities of the oxygen transport system and can predict the risk of postoperative complications [4]. Therefore, PFT and CPET are both indicated for patients with impaired pulmonary function [6].

The aim of this preliminary study was to evaluate the feasibility of exercise testing for predicting postoperative complications in patients with impaired pulmonary function who undergo lung resection.

\section{Materials and Methods}

The study was approved by the institutional review board of our hospital. This study comprised 13 male patients with impaired pulmonary function who were candidates for lung resection. They were prospectively enrolled from August 2011 through August 2013 after providing informed consent. Impaired pulmonary function was defined as follows: Forced expiratory volume in one second $\left(\mathrm{FEV}_{1.0} \%\right)$ /Forced vital capacity (FVC) less than $70 \%$ and emphysema score higher than 8 points by the Goddard classification or interstitial pneumonia on chest computed tomography [7]. Preoperative functional evaluation consisted of spirometry, DLco, and exercise testing, as follows: six-minute walking test (6MWT) and stair-climbing test (SCT).

The following spirometric variables were considered: $\mathrm{FEV}_{1.0}$; predicted postoperative (ppo) $\mathrm{FEV}_{1.0}$ (ppo $\mathrm{FEV}_{1.0}$ [preoperative $\mathrm{FEV}_{1.0} \times$ number of postoperative functioning segments/number of preoperative segments]); predictive postoperative DLco (ppoDLco) [(preoperative DLco $\times$ number of postoperative functioning segments/ number of preoperative segments]); and $\mathrm{FEV}_{1.0} / \mathrm{FVC}[2]$.

The 6MWT is a simple, practical test that requires a $100-\mathrm{ft}$ hallway, but no exercise equipment or advanced training for technicians [8]. This test measures the distance that a patient can quickly walk on a hard, flat surface during a 6-min period. The SCT is also a practical test that measures the total height of stairs a patient can climb [4] [9]. Each stair step is 0.17-m high. The study patients were asked to climb, at their own pace, the maximum number of steps before needing to stop because of exhaustion, limiting dyspnea, leg fatigue, or chest pain. The total number of steps climbed and the time taken to complete the test were recorded for each patient. Each patient's climbing pace was calculated from the total height climbed per time taken to complete the test in minutes. Finger pulse oximetry was used to measure oxygen saturation and pulse rate continuously for both tests.

Each patient was accompanied by a physician during his tests and encouraged to complete the test. Moreover, the physician maintained continuous verbal interaction with the patient to assess dyspnea and the occurrence of other signs/symptoms. The 6MWT and SCT evaluate the global and integrated responses of all the systems involved during exercise, including the pulmonary and cardiovascular systems, systemic circulation, peripheral circulation, neuromuscular units, and muscle metabolism.

Every patient with a concomitant cardiac disease underwent extensive cardiac evaluation before performing the 6MWT and SCT. Concomitant cardiac disease was defined as follows: previous cardiac surgery, previous myocardial infarction, history of coronary artery disease, pulmonary hypertension, an arrhythmia such as atrial 
fibrillation, or cardiac failure. A patient with a concomitant cardiac disease was allowed to undertake the tests after undergoing cardiac evaluation and subsequently considered to be hemodynamically stable. Patients with orthopedic disorders such as herniated intervertebral disks and dysfunction of lower extremities were also excluded from this study because they could not undergo exercise testing.

PCPCs were considered to be cardiopulmonary complications occurring within 30 days after the surgery or those occurring during a longer period if the patient was still in the hospital. According to other reports [10] [11] and for the sake of comparison, the following complications were recorded: respiratory failure requiring mechanical ventilation for $48 \mathrm{~h}$; pneumonia; atelectasis requiring bronchoscopy; pulmonary edema; pulmonary embolism; myocardial infarction; hemodynamically unstable arrhythmia requiring medical treatment; cardiac failure; and death.

\section{Statistical Analysis}

We compared the results of patients who developed PCPCs with those of the patients without PCPCs. Furthermore, we evaluated cut-off values for 6MWT and SCT for use as predictors of postoperative complications. The Mann-Whitney U test was used to analyze continuous variables, and the Fisher exact test to analyze categorical variables. Continuous variables were calculated as mean $\pm \mathrm{SD}$ and categorical variables as number of patients (percent). A $P$-Value $<0.05$ was considered to be statistically significant. Analysis was performed using JMP11 software (SAS Institute Inc., NY, USA).

\section{Results}

Table 1 summarizes the characteristics of the 13 patients. Twelve patients had lung cancer and one patient had metastatic lung cancer. The patients underwent 7 lobectomies and 6 wedge/segment ectomies (limited resections). There were no significant differences between patients with and without PCPCs. Four patients developed the following postoperative pulmonary complications: three patients developed pneumonia and one patient developed pulmonary dysfunction that required home oxygen therapy (Table 2). Two patients with pulmonary complications died in the hospital.

Table 3 shows the PFT and DLco data. There were no significant differences between the patients with and without PCPCs. Table 4 shows the 6MWT and SCT data. The patients who developed PCPCs had a significantly shorter mean preoperative 6MWT distance than the patients without PCPCs. The mean maximum SCT pulse rate and climbing pace of the patients with PCPCs were significantly lower than those of the patients without PCPCs.

We evaluated cut-off values for the CMWT and SCT based on previous reports that indicated that patients with a 6MWT less than $400 \mathrm{~m}$ or SCT height less than $15 \mathrm{~m}$ tended to have postoperative complications [4] [12]. Table 5 shows that three patients who developed PCPCs walked less than 400 min 6 min and none of the patients without PCPCs walked less than $400 \mathrm{~m}(P=0.014)$. Three patients with PCPCs climbed less than $15 \mathrm{~m}$ in the SCT and one patient without PCPCs climbed less than $15 \mathrm{~m}$ (Table $5, P=0.052$ ), and four patients with PCPCs and two patients without PCPCs achieved a climbing paces lower than $8.5 \mathrm{~m} / \mathrm{min}(P=0.021)$. For the 6MWT, a 6-min walking distance shorter than $400 \mathrm{~m}$ had a sensitivity of $75 \%$, specificity of $100 \%$, positive predictive value of $100 \%$ and negative predictive value of $90 \%$ for the development of PCPC. For the SCT, a climbing pace shorter than $8.5 \mathrm{~m} / \mathrm{min}$ had a sensitivity of $100 \%$, specificity of $77.8 \%$, positive predictive value of $66.7 \%$, and negative predictive value of $100 \%$. Conversely, there were no significant differences in the numbers of patients with and without PCPCs who satisfied the traditional criteria of \%ppoDLco less than $40 \%$ and \%ppoFEV1 less than 40\% (Table 5; $P=0.308, P=0.077$, respectively).

\section{Discussion}

We found that 6MWT and SCT were more valid assessments than conventional PFT for predicting the development of PCPCs in our study patients with impaired pulmonary function and emphysema. Although the PFT variables, which were regarded to be predictors of postoperative complications, did not predict PCPCs, the walking distance of the 6MWT and height and climbing pace of the SCT were predictive of PCPCs.

The operability of patients with impaired cardiopulmonary function and type of surgical procedure are traditionally decided using the percent predicted $\mathrm{FEV}_{1.0}$ and percent predicted DLco [12]. Patients with percent 
Table 1. Patient characteristics.

\begin{tabular}{cccc}
\hline Variables & + PCPC $(n=4)$ & NoPCPC $(n=9)$ & $P$-value \\
\hline Age & $78.5 \pm 4.5$ & $74.9 \pm 7.7$ & 0.407 \\
BMI & $18.7 \pm 2.72$ & $22.7 \pm 3.23$ & 0.087 \\
Smoking Index (pack-year) & $57.0 \pm 12.9$ & $40.6 \pm 23.2$ & 0.189 \\
Cardiac Disease, $n$ (\%) & $2(50)$ & $2(22.2)$ & 0.530 \\
Lobectomy, $n$ (\%)/Limited resection & $3(75) / 1(25)$ & $4(44.4) / 5(55.6)$ & 0.559 \\
Blood loss (g) & $1336 \pm 1059$ & $178 \pm 237$ & 0.036 \\
VATS, n (\%) & $4(100)$ & $6(66.7)$ & 0.497 \\
\hline
\end{tabular}

PCPC: postoperative cardiopulmonary complication; BMI: body mass index; VATS: video-assisted thoracic surgery.

Table 2. Type of postoperative complications.

\begin{tabular}{ccccc}
\hline Age (y) & Procedure & Stage-Type & Preoperative disease & Complication \\
\hline 84, Male & Segmentectomy & IA-SCC & COPD & Pneumonia, death \\
78, Male & Lobectomy & IB-SCC & CPFE & Acute respiratory distress syndrome \\
79, Male & Lobectomy & IIIA-Ad & COPD & Hepatic failure, pneumonia, death \\
73, Male & Lobectomy & IIA-SCC & COPD & Respiratory failure \\
\hline
\end{tabular}

SCC: squamous cell carcinoma; Ad: adenocarcinoma; COPD: chronic obstructive pulmonary disease; CPFE: combined pulmonary fibrosis and emphysema.

Table 3. Pulmonary function data.

\begin{tabular}{cccc}
\hline Variables & +PCPC & NoPCPC & $P$-value \\
\hline FVC & $2.50 \pm 0.72$ & $3.28 \pm 0.71$ & 0.189 \\
\%FVC & $80.9 \pm 23.7$ & $101.7 \pm 18.2$ & 0.190 \\
FEV1 & $1.70 \pm 0.43$ & $2.12 \pm 0.67$ & 0.247 \\
\%FEV1 & $85.0 \pm 28.4$ & $97.6 \pm 26.8$ & 0.488 \\
\% ppoFEV1.0 & $67.3 \pm 27.0$ & $85.9 \pm 25.7$ & 0.396 \\
FEV1/FVC\% & $69.6 \pm 13.5$ & $65.5 \pm 18.8$ & 0.939 \\
RV/TLC & $45.9 \pm 18.0$ & $36.9 \pm 8.60$ & 0.671 \\
\%DLco & $77.3 \pm 38.7$ & $80.2 \pm 22.5$ & 0.671 \\
\%DLco/VA & $58.9 \pm 28.5$ & $70.0 \pm 20.3$ & 0.799 \\
PaO 2 & $83.7 \pm 2.33$ & $98.7 \pm 31.5$ & 0.552 \\
PaCO & $38.2 \pm 6.15$ & $37.0 \pm 6.23$ & 1.000 \\
CT evaluation & & & 0.0601 \\
Goddard Score & $9.75 \pm 4.35$ & $4.00 \pm 7.16$ & 0.2028 \\
PF, $n$ (\%) & $2(50)$ & $1(11)$ & \\
\hline
\end{tabular}

PCPC: postoperative cardiopulmonary complication; ppo: predicted postoperative: DLco: diffusing capacity of the lung for carbon monoxide: VA: alveolar ventilation; PF: pulmonary fibrosis.

Table 4. 6MWT and SCT data.

\begin{tabular}{cccc}
\hline Variables & + PCPC & NoPCPC & $P$-value \\
\hline Distance in6MWT (m) & $369 \pm 50.7$ & $503 \pm 72.7$ & 0.011 \\
Minimum SpO in $_{2}$ (MWT (\%) & $84.3 \pm 6.70$ & $89.9 \pm 6.03$ & 0.213 \\
Maximum PR in 6MWT & $103 \pm 6.93$ & $118.9 \pm 19.6$ & 0.142 \\
SCT height (m) & $14.9 \pm 4.00$ & $20.4 \pm 5.31$ & 0.187 \\
Minimum SpO in SCT (\%) & $83.3 \pm 7.29$ & $89.3 \pm 4.90$ & 0.133 \\
Maximum PR in SCT & $109 \pm 8.0$ & $132 \pm 14.5$ & 0.030 \\
SCT climbing time (min) & $2.32 \pm 0.91$ & $2.05 \pm 1.29$ & 0.480 \\
SCT climbing pace (m/min) & $6.8 \pm 0.87$ & $11.8 \pm 4.11$ & 0.045
\end{tabular}

PCPC: postoperative cardiopulmonary complication; 6MWT: six-minute walk test; SCT: stair climbing test; $\mathrm{SpO}_{2}$ : oxygen saturation; PR: pulse rate. 
Table 5. Cut-off values of selected variables.

\begin{tabular}{cccc}
\hline Cut-off values & + PCPC $(n, \%)$ & NoPCPC $(n, \%)$ & $P$-value \\
\hline Distance in 6MWT $<400 \mathrm{~m}$ & $3(75)$ & $0(0)$ & 0.014 \\
Heightin SCT $<15 \mathrm{~m}$ & $3(75)$ & $1(11)$ & 0.052 \\
Pacein SCT $<8.5 \mathrm{~m} / \mathrm{min}$ & $4(100)$ & $2(22)$ & 0.021 \\
\%ppoFEV1.0 $<40 \%$ & $1(25)$ & $0(0)$ & 0.308 \\
\%ppoDLco $<40 \%$ & $2(50)$ & $0(0)$ & 0.077
\end{tabular}

PCPC: postoperative cardiopulmonary complication; ppo: predicted postoperative value.

predicted $\mathrm{FEV}_{1.0}$ and percent predicted DLco $>40 \%$ are considered to be operable [12]. These standards are meaningful but not always predictive of the development of PCPCs without the addition of other tests [13]. Various tests and scoring systems have been reported [14]-[18]. A modified Thoracoscore, which predicts postoperative outcomes after thoracic surgery, can be calculated based on the following variables: age, gender, priority of the procedure, malignancy, type of procedure, Zubrod score, ASA class, and number of co-morbidities [18]. However, such a scoring system is difficult to use on a daily basis in clinical practice.

The 6MWT and SCT are global exercise tests that can evaluate cardiopulmonary function, particularly for patients with chronic obstructive pulmonary disease (COPD) [8] [13]. These tests consist of the following variables: distance walked, height climbed, change in SpO2, maximum pulse rate, and SCT pace [4] [13].

There were no significant differences in the traditional PFT results for the patients with and without PCPCs. Three of four patients developing PCPCs had percentppoFEV $V_{1.0}>40 \%$. This finding indicates that the patient's condition may be underestimated if only traditional PFT data is used.

This prospective study has some limitations and biases. First, this was a small dataset from a single-center study. Therefore, there may be several confounding variables, and a large prospective study is needed to verify the findings. Second, there was no single surgical procedure, because the type of procedure used was based on lung cancer stage and the patient's physical condition. Third, COPD should not be defined by functional limitation and radiologic evaluation only. Other clinical criteria should have been taken into consideration [19]. It is possible that the use of other criteria for COPD could have produced different results.

\section{Conclusion}

For lung cancer patients with impaired pulmonary function, exercise testing is more feasible for predicting postoperative cardiopulmonary complications than stationary pulmonary function testing. 6MWT $<400 \mathrm{~m}$, SCT height $<15 \mathrm{~m}$, and SCT climbing pace $<8.5 \mathrm{~m} / \mathrm{min}$ are useful values for predicting postoperative cardiopulmonary complications.

\section{Disclosure Statements}

All authors have no conflict of interest.

\section{References}

[1] Colice, G.L., Shafazand, S., Griffin, J.P., Keenan, R. and Bolliger, C.T., American College of Chest Physicians (2007) Physiologic Evaluation of the Patient with Lung Cancer Being Considered for Resectional Surgery: ACCP EvidencedBased Clinical Practice Guidelines (2nd Edition). Chest, 132, 161S-177S.

[2] Sekine, Y., Iwata, T., Chiyo, M., Yasufuku, K., Motohashi, S., Yoshida, S., et al. (2003) Minimal Alteration of Pulmonary Function after Lobectomy in Lung Cancer Patients with COPD. The Annals of Thoracic Surgery, 76, 356-361. http://dx.doi.org/10.1016/S0003-4975(03)00489-2

[3] Fishman, A., Martinez, F., Naunheim, K., Piantadosi, S., Wise, R., Ries, A., et al. (2003) National Emphysema Treatment Trial Research Group. A Randomized Trial Comparing Lung-Volume-Reduction Surgery with Medical Therapy for Severe Emphysema. The New England Journal of Medicine, 348, 2059-2073. http://dx.doi.org/10.1056/NEJMoa030287

[4] Brunelli, A., Al Refai, M., Monteverde, M., Borri, A., Salati, M. and Fianchini, A. (2002) Stair Climbing Test Predicts Cardiopulmonary Complications after Lung Resection. Chest, 121, 1106-1110.

http://dx.doi.org/10.1378/chest.121.4.1106 
[5] Olsen, G.N. (1989) The Evolving Role of Exercise Testing Prior to Lung Resection. Chest, 95, 218-225. http://dx.doi.org/10.1378/chest.95.1.218

[6] Datta, D. and Lahiri, B. (2003) Preoperative Evaluation of Patients Undergoing Lung Resection Surgery. Chest, 123, 2096-2103. http://dx.doi.org/10.1378/chest.123.6.2096

[7] Goddard, P.R., Nicholson, E.M., Laszlo, G. and Watt, I. (1992) Computed Tomography in Pulmonary Emphysema. Clinical Radiology, 33, 379-387. http://dx.doi.org/10.1016/S0009-9260(82)80301-2

[8] ATS Committee on Proficiency Standards for Clinical Pulmonary Function Laboratories (2002) ATS Statement: Guidelines for the Six-Minute Walk Test. American Journal of Respiratory and Critical Care Medicine, 166, 111-117. http://dx.doi.org/10.1164/ajrccm.166.1.at1102

[9] Olsen, G.N., Bolton, J.W., Weiman, D.S. and Hornung, C.A. (1991) Stair Climbing as an Exercise Test to Predict Perioperative Complications of Lung Resection: Two Years’ Experience. Chest, 99, 587-590. http://dx.doi.org/10.1378/chest.99.3.587

[10] Bechard, D. and Wetstein, L. (1987) Assessment of Exercise Oxygen Consumption as Preoperative Criterion for Lung Resection. The Annals of Thoracic Surgery, 44, 344-349. http://dx.doi.org/10.1016/S0003-4975(10)63787-3

[11] Bolliger, C.T., Jordan, P., Solèr, M., Stulz, P., Grädel, E., Skarvan, K., et al. (1995) Exercise Capacity as a Predictor of Postoperative Complications in Lung Resection Candidates. American Journal of Respiratory and Critical Care Medicine, 151, 1472-1480. http://dx.doi.org/10.1164/ajrccm.151.5.7735602

[12] Keagy, B.A., Schorlemmer, C.R., Murray, G.F., Starek, P.J.K. and Wilcox, B.R. (1983) Correlation of Preoperative Pulmonary Function Testing with Clinical Course in Patients after Pneumonectomy. The Annals of Thoracic Surgery, 36, 253-257.

[13] Holden, D.A., Rice, T.W., Stelmach, K. and Meeker, D.P. (1992) Exercising Testing, 6-min Walk, and Stair Climb in the Evaluation of Patients at High Risk for Pulmonary Resection. Chest, 102, 1774-1779. http://dx.doi.org/10.1378/chest.102.6.1774

[14] Barua, A., Handagala, S.D., Socci, L., Barua, B., Malik, M., Johnstone, N. and Martin-Ucar, A.E. (2012) Accuracy of Two Scoring Systems for Risk Stratification in Thoracic Surgery. Interactive CardioVasc Thoracic Surgery, 14, 566569. http://dx.doi.org/10.1093/icvts/ivs021

[15] Lim, E., Baldwin, D., Beckles, M., Duffy, J., Entwisle, J., Faivre-Finn, C., et al. (2010) Guidelines on the Radical Management of Patients with Lung Cancer. Thorax, 65, iii1-iii27. http://dx.doi.org/10.1136/thx.2010.145938

[16] Brunelli, A., Morgan-Hughes, N.J., Refai, M., Slati, M., Sabbatini, A. and Rocco, G. (2007) Risk-Adjusted Morbidity and Mortality Models to Compare the Performance of Two Units after Major Lung Resections. The Journal of Thoracic and Cardiovascular Surgery, 133, 88-96. http://dx.doi.org/10.1016/j.jtcvs.2006.08.058

[17] Falcoz, P.E., Conti, M., Brouchet, L., Chocron, S., Mercier, M., Etievent, J.P., et al. (2007) The Thoracic Surgery Scoring System (Thoracoscore): Risk Model for In-Hospital Death in 15,183 Patients Requiring Thoracic Surgery. The Journal of Thoracic and Cardiovascular Surgery, 133, 325-332. http://dx.doi.org/10.1016/j.jtcvs.2006.09.020

[18] Chamogeorgakis, T., Toumpoulis, I., Tomos, P., Ieromonachos, C., Angouras, D., Georgiannakis, E., et al. (2009) External Validation of the Modified Thoracoscore in a New Thoracic Surgery Program: Prediction of In-Hospital Mortality. Interactive CardioVasc Thoracic Surgery, 9, 463-466. http://dx.doi.org/10.1510/icvts.2008.201178

[19] Celli, B.R., Halbert, R.J., Isonaka, S. and Schau, B. (2003) Population Impact of Different Definitions of Airway Obstruction. European Respiratory Journal, 22, 268-273. http://dx.doi.org/10.1183/09031936.03.00075102 